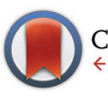

CrossMark

\&click for updates

Cite this: Polym. Chem., 2015, 6 , 7988

Received 20th August 2015,

Accepted 24th September 2015

DOI: $10.1039 / c 5 p y 01329 a$

www.rsc.org/polymers

\section{One-pot synthesis and self-assembly of supramolecular dendritic polymers $\uparrow$}

\author{
Senbin Chen, ${ }^{a}$ Matthias Schulz, ${ }^{a}$ Bob-Dan Lechner, ${ }^{\mathrm{b}}$ Clement Appiah ${ }^{\mathrm{a}}$ and \\ Wolfgang $\mathrm{H}$. Binder ${ }^{\star a}$
}

We report the design and synthesis of novel supramolecular dendrimers, formed by the association of $\mathrm{X}-\mathrm{Y}_{2}$ type single-chain polymeric building blocks Ba-(PnBuA-HW)$)_{2}$, with (poly(n-butyl acrylate) PnBuA) separating the two specific interacting supramolecular moieties $X$ (barbiturate, $\mathrm{Ba}$ ) and $\mathrm{Y}$ (Hamilton wedge, $H W$ ). Based on a one-pot two-step synthesis, the mid-Ba and $\alpha, \omega-H W$ functionalized $X-Y_{2}$ type polymer, $\mathrm{Ba}-(\mathrm{PnBuA}-\mathrm{HW})_{2}$, is generated via a direct thiol-bromo click reaction with $\mathrm{Ba}-(\mathrm{PnBuA}-\mathrm{RAFT})_{2},\left(M_{n, \mathrm{NMR}}=\right.$ $5.0 \mathrm{kDa}, M_{\mathrm{n}, \mathrm{SEC}}=4.8 \mathrm{kDa}, \Theta=1.25$, prepared via reversible addition-fragmentation chain transfer (RAFT) polymerization), successfully attaching the heterocomplementary supramolecular moieties (HW) at both chain ends in a one-pot fashion at room temperature within one hour. The so obtained $\mathrm{Ba}-(\mathrm{PnBuA}-\mathrm{HW})_{2}$ $\left(M_{n, N M R}=7.1 \mathrm{kDa}, M_{\mathrm{n}, \mathrm{SEC}}=6.7 \mathrm{kDa}, \oplus=1.23\right)$ assembles into supramolecular dendritic polymers via hydrogen-bonds ( $\mathrm{H}$-bonds), illustrating impressive viscosity enhancement in the bulk state (at $20^{\circ} \mathrm{C}$ by a factor as high as $~ 1839$ ). Atomic force microscopy (AFM) investigations reveal large but defined disc-like objects when spin-coated from a $\mathrm{Ba}-(\mathrm{PnBuA}-\mathrm{HW})_{2}$ solution, enabling to tune morphology at the mesoscale to generate hierarchical strucutures by choice of the solvent.

\section{Introduction}

Taking advantage of hydrogen bonds as specific supramolecular interactions, impressive progress has been achieved in the construction of various supramolecular architectures during the last decade, ${ }^{1-7}$ such as supramolecular blockcopolymers, ${ }^{8-13}$ (miktoarm) ${\text { star-shaped, }{ }^{14-17} \text { H-shaped }}^{18,48}$ and comb/brush-shaped ${ }^{19-22}$ architectures or even more complex supramolecular aggregates. ${ }^{23-27}$

Among those, the design of supramolecular dendritic architectures is special, as it requires appropriate design of the assembling components. Thus one widely investigated synthetic strategy relies on mixing two heterocomplementary components, namely $\mathrm{X}_{n}$ and $\mathrm{Y}_{m}$, where $n \geq 2$ and $m \geq 3,{ }^{28}$ or via self-organization of a $\mathrm{X}-\mathrm{Y}_{n}(n \geq 2)$ type single-chain building block-an approach, where only few examples ${ }^{29-32}$ have been

\footnotetext{
${ }^{a}$ Chair of Macromolecular Chemistry, Faculty of Natural Science II (Chemistry, Physics and Mathematics), Martin-Luther University Halle-Wittenberg, vonDanckelmann-Platz 4, Halle (Saale) D-06120, Germany.

E-mail: wolfgang.binder@chemie.uni-halle.de

${ }^{b}$ Physical Chemistry, Faculty of Natural Sciences II (Chemistry, Physics and Mathematics), Martin-Luther University Halle-Wittenberg, von-Danckelmann-Platz 4, Halle (Saale) D-06120, Germany

$\dagger$ Electronic supplementary information (ESI) available: Details of polymerization and synthesis, SEC traces, MALDI-TOF MS spectroscopy, temperature-dependent rheology, shear modulus studies, SAXS profile, AFM height images and DOSY NMR spectrum. See DOI: 10.1039/c5py01329a
}

reported, all of them focusing on low-molecular-weight compound systems. To the best of our knowledge, the preparation of $\mathrm{X}-\mathrm{Y}_{n}(n \geq 2)$ type single-chain polymeric macromolecules has not been exploited, presumably due to the tedious synthesis requiring a complete attachment of supramolecular entities - an issue which is often hampered by less robust chemistries and/or time-consuming complicated purification procedures, especially when applied onto polymers as the central scaffold.

It is known that the advance of click reaction ${ }^{33,34}$ has paved a way for new opportunities in the fabrication of supramolecular architectures based on polymeric macromolecules. ${ }^{4,35-38}$ In addition to the well-known copper-catalysed alkyne-azide cycloaddition click reaction, ${ }^{39}$ metal-free thiol-based chemistries have been also identified as a highly robust synthetic approach recently. ${ }^{40,41}$ Compared to other thiol-based efficient coupling reactions, such as the thiol-ene, the thiol-yne, the thiol-isocyanate and the thiol-epoxy reaction, the investigation of the thiol-bromo click reaction still remains limited, ${ }^{42}$ although several examples have been reported very recently. ${ }^{43-47}$

We here describe the synthesis of novel supramolecular dendritic polymers using $\mathrm{X}-\mathrm{Y}_{2}$ type heterotropic single-chain polymers, namely the mid-Ba and $\alpha, \omega-\mathrm{HW}$ functionalized polymer $\mathrm{Ba}-(\mathrm{P} n \mathrm{BuA}-\mathrm{HW})_{2}$, where $\mathrm{P} n \mathrm{BuA}$ is separating the two specific interacting supramolecular moieties $\mathrm{X}$ (Ba) and $\mathrm{Y}(\mathrm{HW})$. We are using a one-pot two-step reaction, successfully linking the HW moieties onto both polymer chain ends 
directly after the polymerization reaction. From its design we target the generation of a $\mathrm{X}-\mathrm{Y}_{2}$ architecture, equipped with the $\mathrm{Ba} / \mathrm{HW}$ moieties, displaying a high association constant of approximately $10^{5} \mathrm{M}^{-1},{ }^{11}$ in turn leading to the formation of a non-crosslinked, dendritic macromolecule via supramolecular specific association. The synthesis of the $\mathrm{X}-\mathrm{Y}_{2}$ type heterotropic single-chain polymer $\mathrm{Ba}-(\mathrm{P} n \mathrm{BuA}-\mathrm{HW})_{2}$ relies on the combination of the thiol-bromo click reaction together with a PnBuA-polymer prepared by RAFT polymerization. The easy, yet complete conversion of the dithioester moiety of the RAFTmade polymer into a reactive thiol group via aminolysis facilitates the subsequent direct polymer functionalization relying on the above mentioned thiol-based efficient coupling reaction (Fig. 1). ${ }^{40}$ Subsequent association yields the expected supramolecular dendrimers, displaying large but defined disc-like nanoscopic structures spin-coated from a $\mathrm{Ba}-(\mathrm{P} n \mathrm{BuA}-\mathrm{HW})_{2}$

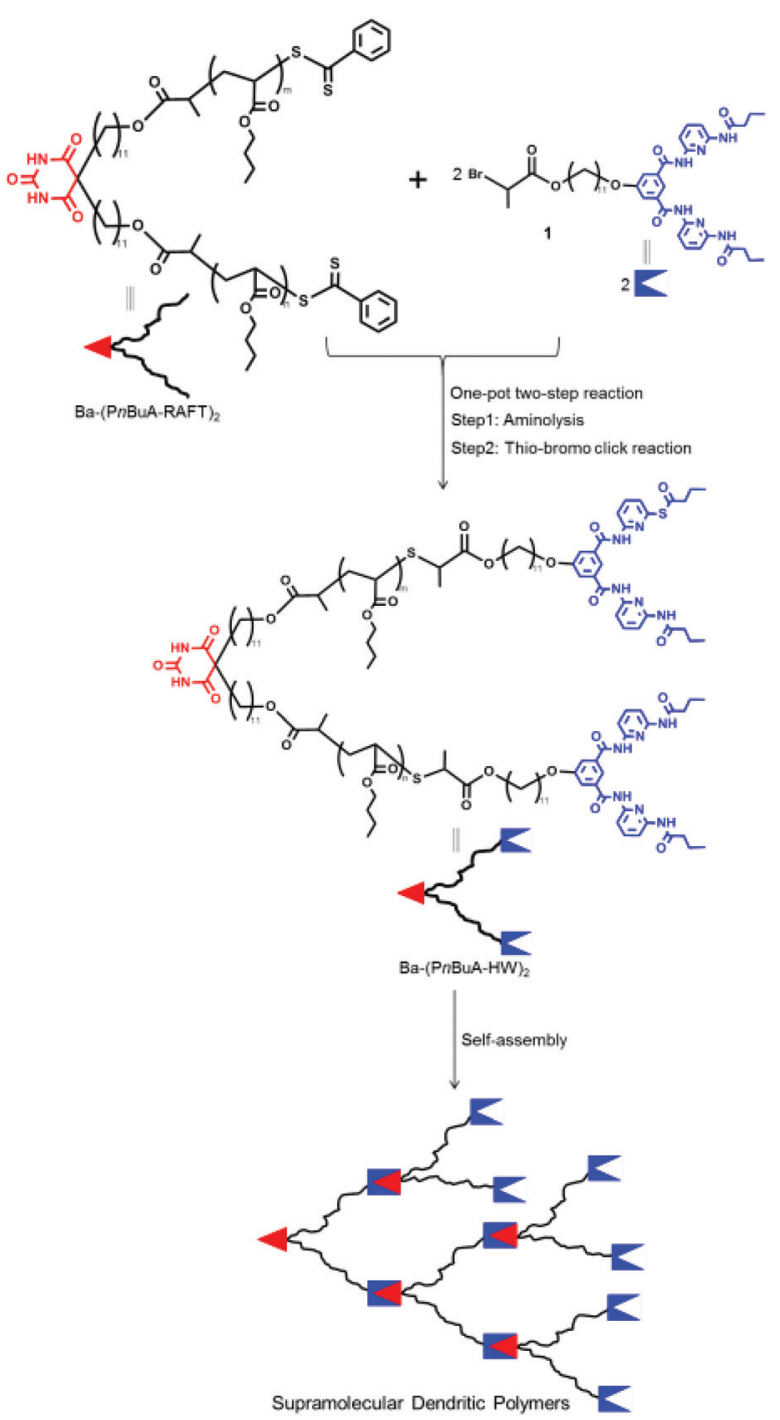

Fig. 1 Synthetic route to the mid-Ba and $\alpha, \omega-H W$ functionalized $X-Y_{2}$ type polymer Ba-(PnBuA-HW $)_{2}$ and its self-assembly to afford the supramolecular dendritic polymers. solution in chloroform. Moreover, the disc-like structures can be tuned to generate hierarchical morphologies by changing the solvent from chloroform to less polar toluene.

\section{Results and discussion}

\section{Design, synthesis and structure characterization of the $\mathrm{X}-\mathrm{Y}_{2}$ type polymer Ba-(PnBuA-HW $)_{2}$}

Aiming at fabricating the mid-Ba and $\alpha, \omega-\mathrm{HW}$ functionalized $\mathrm{X}-\mathrm{Y}_{2}$ type polymer $\mathrm{Ba}-(\mathrm{P} n \mathrm{BuA}-\mathrm{HW})_{2}$ (Fig. 1), we have first prepared mid-Ba functionalized polymer $\mathrm{Ba}-(\mathrm{P} n \mathrm{BuA}-\mathrm{RAFT})_{2}\left(M_{\mathrm{n}}\right.$, NMR $=5.0 \mathrm{kDa}, M_{\mathrm{n}, \mathrm{SEC}}=4.8 \mathrm{kDa}, D=1.25$, ESI, Fig. $\mathrm{S} 1$ and $\mathrm{S} 2 \dagger) .{ }^{48}$ Subsequently, the $\alpha, \omega$-dithiobenzoate end groups of the so prepared $\mathrm{Ba}-(\mathrm{P} n \mathrm{BuA}-\mathrm{RAFT})_{2}$ are cleaved to thiols via an aminolysis reaction, directly reacting the in situ generated thiols with compound $1,{ }^{49}$ a bromoester bearing a Hamilton wedge, in one-pot fashion. Although acetonitrile is unable to fully dissolve $\mathrm{Ba}-(\mathrm{P} n \mathrm{BuA}-\mathrm{RAFT})_{2}$, the one-pot two-step reaction is completed at room temperature within one hour. The targeted $\mathrm{X}-\mathrm{Y}_{2}$ type polymer, $\mathrm{Ba}-(\mathrm{P} n \mathrm{BuA}-\mathrm{HW})_{2}$, is purified by precipitation into methanol/water $(1 / 1, v / v)$ and then silica column chromatography (dichloromethane/methanol, 30/1, $\mathrm{v} / \mathrm{v})$. The obtained product $\mathrm{Ba}-(\mathrm{P} n \mathrm{BuA}-\mathrm{HW})_{2}$ is subsequently analysed by size exclusion chromatography $\left(\mathrm{SEC}, M_{\mathrm{n}, \mathrm{SEC}}=\right.$ $6.7 \mathrm{kDa}, \emptyset=1.23$, ESI, Fig. S2 $\dagger$ ).

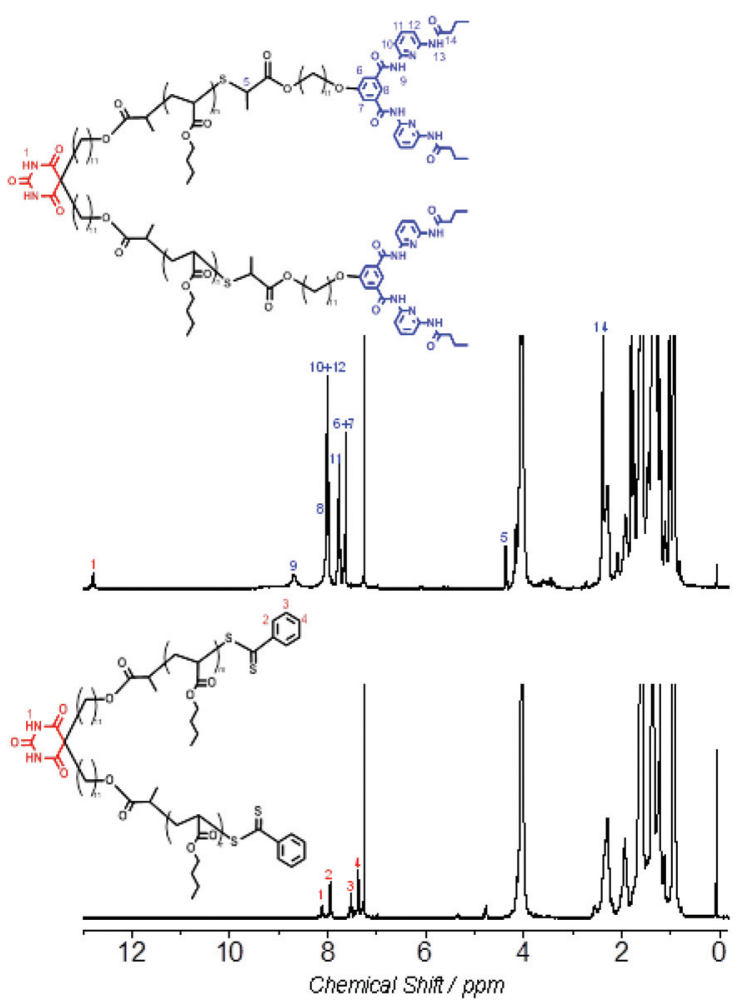

Fig. $2{ }^{1} \mathrm{H}$ NMR spectra of $\mathrm{Ba}-(\mathrm{PnBuA}-\mathrm{RAFT})_{2}$ (bottom), and $\mathrm{Ba}$ $(\mathrm{PnBuA}-\mathrm{HW})_{2}$ (top) at $27{ }^{\circ} \mathrm{C}$ in $\mathrm{CDCl}_{3}$ ([Ba-(PnBuA-RAFT) $\left.)_{2}\right]=[\mathrm{Ba}-$ $\left.\left.(\mathrm{PnBuA}-\mathrm{HW})_{2}\right]=2 \mathrm{mM}\right)$. The second imide peak of Hamilton wedge is overlapping with the aromatic protons in the top spectrum. 


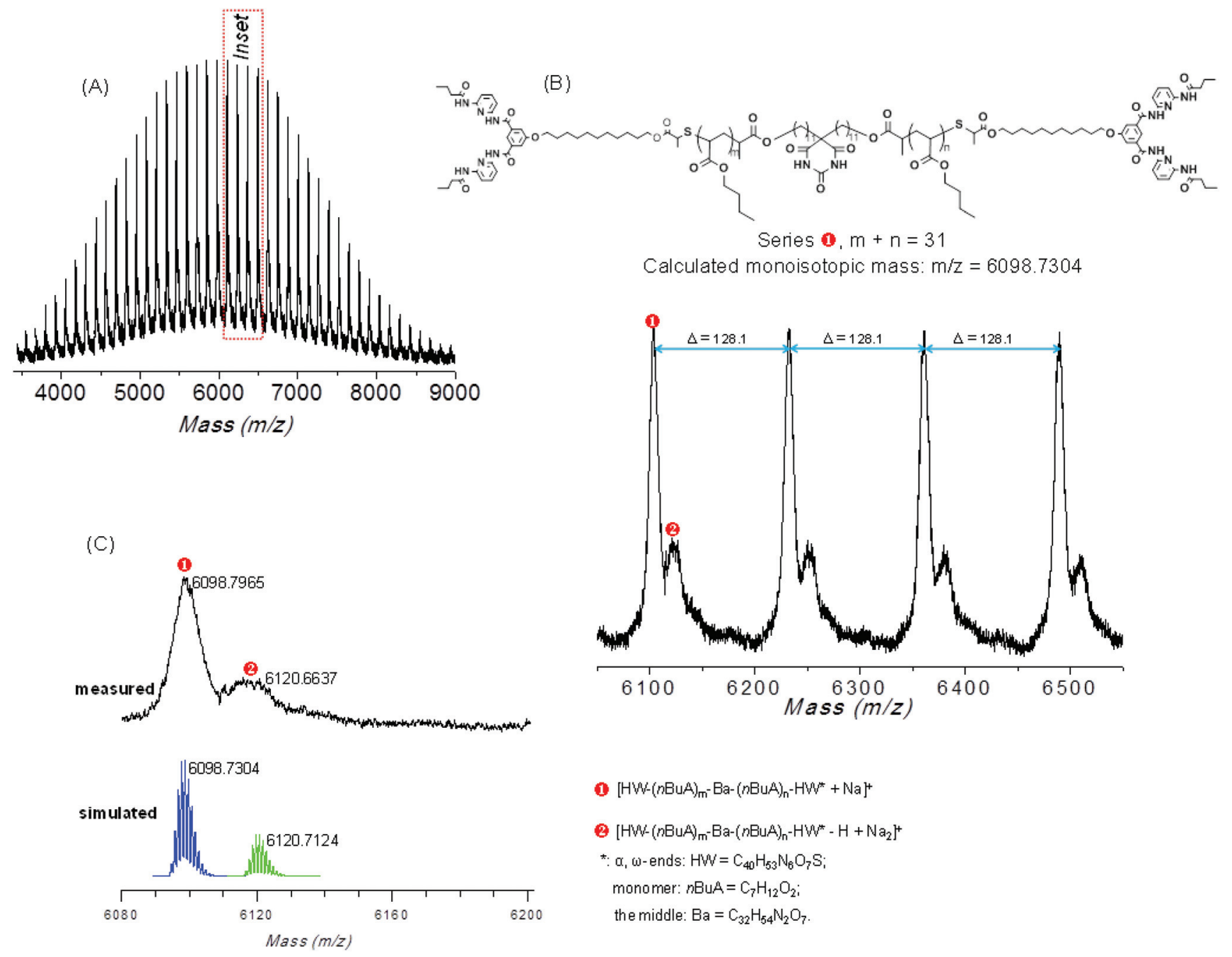

Fig. 3 MALDI-TOF MS of Ba-(PnBuA-HW) 2 (A) full spectrum, (B) expansion and (C) simulation of the isotope pattern.

Primary evidence of the successful synthesis of the mid-Ba and $\alpha, \omega$-HW functionalized $\mathrm{X}-\mathrm{Y}_{2}$ type polymer $\mathrm{Ba}-(\mathrm{P} n \mathrm{BuA}-\mathrm{HW})_{2}$ is provided by ${ }^{1} \mathrm{H}$ NMR (Fig. 2). Compared to the spectrum of the starting material, Ba-(PnBuA-RAFT $)_{2}$, the complete disappearance of the characteristic phenyl protons (7.95, 7.53 and 7.39 ppm in Fig. 2, bottom) ortho to the dithiobenzoate group, along with the emergence of the Hamilton wedge imide protons (8.68 ppm in Fig. 2, top), as well as the pyridyl and phenyl protons (8.02, 7.77 and 7.63 ppm in Fig. 2, top) indicates the successful linking of HW moieties onto the polymer chain ends.

Furthermore, matrix-assisted laser desorption/ionizationtime of flight mass (MALDI-TOF MS) spectrometry has been used to prove the attachment of two HW moieties via the thiol-bromo click reaction. Mass spectra of the starting material $\mathrm{Ba}-(\mathrm{P} n \mathrm{BuA}-\mathrm{RAFT})_{2}$ and final product $\mathrm{Ba}-(\mathrm{P} n \mathrm{BuA}-\mathrm{HW})_{2}$ are shown in the linear mode, (see Fig. S3A and $\mathrm{C}\left(\mathrm{ESI}^{\dagger}\right)$ ) obtained by ionization of polymer chains assisted with dithranol as matrix and sodium iodide as the cationization agent. As seen in Fig. S3 (ESI†), comparing the MALDI-TOF spectrum of

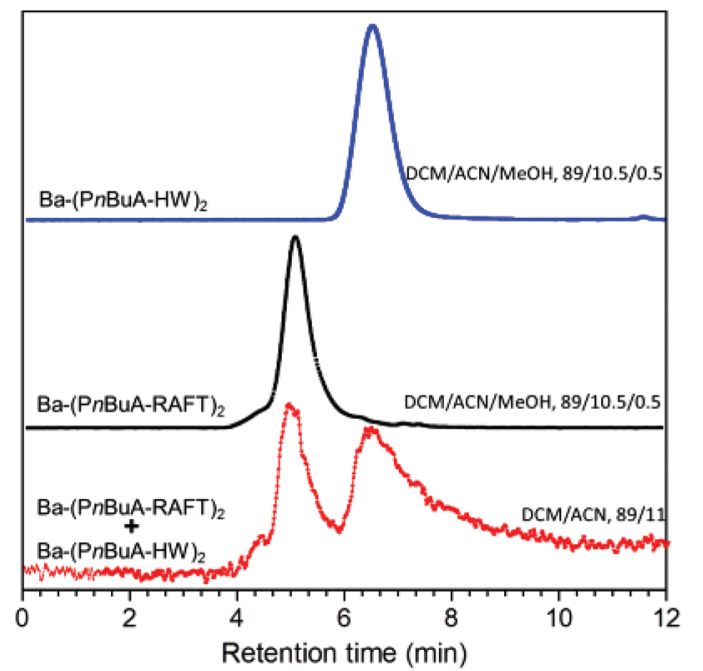

Fig. 4 LC chromatograms at LCCC conditions for a defined 1/1-mixture of Ba-(PnBuA-RAFT) $)_{2}$ with Ba-(PnBuA-HW $)_{2}$ (bottom), Ba-(PnBuA-RAFT) ${ }_{2}$ (middle) and pure $\mathrm{Ba}-(\mathrm{PnBuA}-\mathrm{HW})_{2}$ (top) showing excellent separation based on their functionality. 
$\mathrm{Ba}-(\mathrm{P} n \mathrm{BuA}-\mathrm{HW})_{2}$ (ESI, Fig. S3A $\dagger$ ) to the initial starting material Ba-(PnBuA-RAFT) ${ }_{2}$ (ESI, Fig. S3C $\dagger$ ), the shift towards high mass clearly indicates the successful attachment of both HW moieties via the thiol-bromo-click reaction. Both MALDI-TOF spectra (ESI, Fig. S3B and $\mathrm{D}^{\dagger}$ ) underline the presence of a main series (1 and (1) refer, respectively, to $\mathrm{Ba}-(\mathrm{P} n \mathrm{BuA}-\mathrm{HW})_{2}$ and $\left.\mathrm{Ba}-(\mathrm{P} n \mathrm{BuA}-\mathrm{RAFT})_{2}\right)$, along with other minor series (2, (2) \& (3)): each set of ions is separated by $128.1 \mathrm{Da}$, reflecting the repeating unit of the $n \mathrm{BuA}$ monomer (calculated $128.08 \mathrm{Da}$ ). The detailed simulation of MALDI-TOF MS spectrometry for $\mathrm{Ba}-(\mathrm{P} n \mathrm{BuA}-\mathrm{HW})_{2}$ (Fig. 3A, corresponding to Fig. S3A in the ESI $\dagger$ ) is subsequently accomplished, proving the assignment of the main series (a), located at 6098.7965 Da (Fig. 3C), to a mid-Ba, $\alpha, \omega-\mathrm{HW}$ functionalized species $\left[\mathrm{Ba}-\left(n \mathrm{BuA}_{15.5}-\mathrm{HW}\right)_{2}+\right.$ $\mathrm{Na}]^{+}$, i.e., $\left[\mathrm{C}_{32} \mathrm{H}_{54} \mathrm{~N}_{2} \mathrm{O}_{7}-\left(\left(\mathrm{C}_{7} \mathrm{H}_{12} \mathrm{O}_{2}\right)_{15.5}-\mathrm{C}_{40} \mathrm{H}_{53} \mathrm{~N}_{6} \mathrm{O}_{7} \mathrm{~S}\right)_{2}+\mathrm{Na}\right]^{+}$, which matches well with the simulated pattern $\left(\mathrm{m} / \mathrm{z}_{\text {average }}=\right.$ $6098.7304 \mathrm{Da})$. The observed isotopic patterns of the minor series (2), illustrated in Fig. 3B and C, also agree well with the simulated structure, proving that the one-pot two-step reaction proceeded efficiently, thus further ascertaining the successful macromolecular modification, also showing no residual trace of an only mono- or non-functionalized polymer.

However, to fully establish a complete end-group transformation from $\mathrm{Ba}-(\mathrm{P} n \mathrm{BuA}-\mathrm{RAFT})_{2}$ to $\mathrm{Ba}-(\mathrm{P} n \mathrm{BuA}-\mathrm{HW})_{2}$, liquid chromatography at critical conditions (LCCC) is conducted (Fig. 4). To this end, Ba-(PnBuA-RAFT $)_{2}$ and $\mathrm{Ba}-(\mathrm{P} n \mathrm{BuA}-\mathrm{HW})_{2}$ are subsequently characterized by LC at near-critical conditions (dichloromethane/acetonitrile, DCM/ACN, 89/11, v/v at $25^{\circ} \mathrm{C}$ ) reported for $\mathrm{P} n \mathrm{BuA} .{ }^{50} \mathrm{Ba}-(\mathrm{P} n \mathrm{BuA}-\mathrm{HW})_{2}$ under these conditions is however partially retained on the reversed phase Atlantis column. Thus, overcoming this retention-effect is accomplished by adding $0.5 \%$ methanol $(\mathrm{MeOH})$ to the mobile phase (i.e. DCM/ACN/MeOH, 89/10.5/0.5, v/v/v). As seen in Fig. 4 (bottom) for the mixed sample (Ba-(PnBuA-RAFT) $)_{2}+$ $\left.\mathrm{Ba}-(\mathrm{P} n \mathrm{BuA}-\mathrm{HW})_{2}\right)$, no major changes in the retention time compared to the pure $\mathrm{Ba}-(\mathrm{P} n \mathrm{BuA}-\mathrm{RAFT})_{2}$ (Fig. 4, middle) is observed, indicating that the $0.5 \%$ methanol addition does not have any negative effect on the LCCC conditions, but rather helped in solubilising the polar end-group to enhance a better movement of the polymer in the column. Most importantly, the results from the LC show different retention times for Ba$(\mathrm{P} n \mathrm{BuA}-\mathrm{RAFT})_{2}$ (4.65 min, Fig. 4, middle) and Ba-(PnBuA-HW $)_{2}$ (6.26 min, Fig. 4, top). The signal of the starting polymer Ba$(\mathrm{P} n \mathrm{BuA}-\mathrm{RAFT})_{2}$ is not present in the spectrum of final pure Ba$(\mathrm{P} n \mathrm{BuA}-\mathrm{HW})_{2}$ (see Fig. 4/top), which undoubtedly confirms the successful macromolecular conversion via the thiol-bromo click reaction.

\section{Characterization of $\mathrm{Ba}-(\mathrm{PnBuA}-\mathrm{HW})_{2}$ self-assembly}

Upon confirming the expected structure and purity of Ba$(\mathrm{P} n \mathrm{BuA}-\mathrm{HW})_{2}$ prepared via the one-pot two-step reaction, we subsequently question the self-assembly behaviour, both in solution and in the bulk state.

A first indication of self-assembly of Ba-(PnBuA-HW $)_{2}$ is provided by ${ }^{1} \mathrm{H}$ NMR studies (Fig. 2). Compared to the spectrum of $\mathrm{Ba}-(\mathrm{P} n \mathrm{BuA}-\mathrm{RAFT})_{2}$ (Fig. 2, bottom), in addition to the appearance of Hamilton wedge protons in the expected stoichiometric amounts, a considerable downfield shift of the barbiturate imide protons from 8.12 to 12.79 ppm is observed: a strong indication for the formation of the expected $\mathrm{H}$-bonded complex (Fig. 2, top). In order to prove the effect of $\mathrm{H}$-bonding more clearly, the addition of small amounts of a polar solvent MeOD- $\mathrm{d}_{4}$ into the $\mathrm{CDCl}_{3}$ solution is performed (Fig. 5), which leads to a significant upfield shift of the barbiturate $\mathrm{NH}$ protons to 10.89 and 10.54 ppm in Fig. 5B and C, respectively, revealing the partial dissociation of the supramolecular structures by action of the hydrogen breaking solvent. It is also noteworthy that the barbiturate $\mathrm{NH}$ protons are difficult to detect in the mixed solvent of $\mathrm{CDCl}_{3} / \mathrm{MeOD}-\mathrm{d}_{4}$ (Fig. 5B and C).

Rheological measurements have been subsequently performed in the bulk state to achieve more insight into the relax-

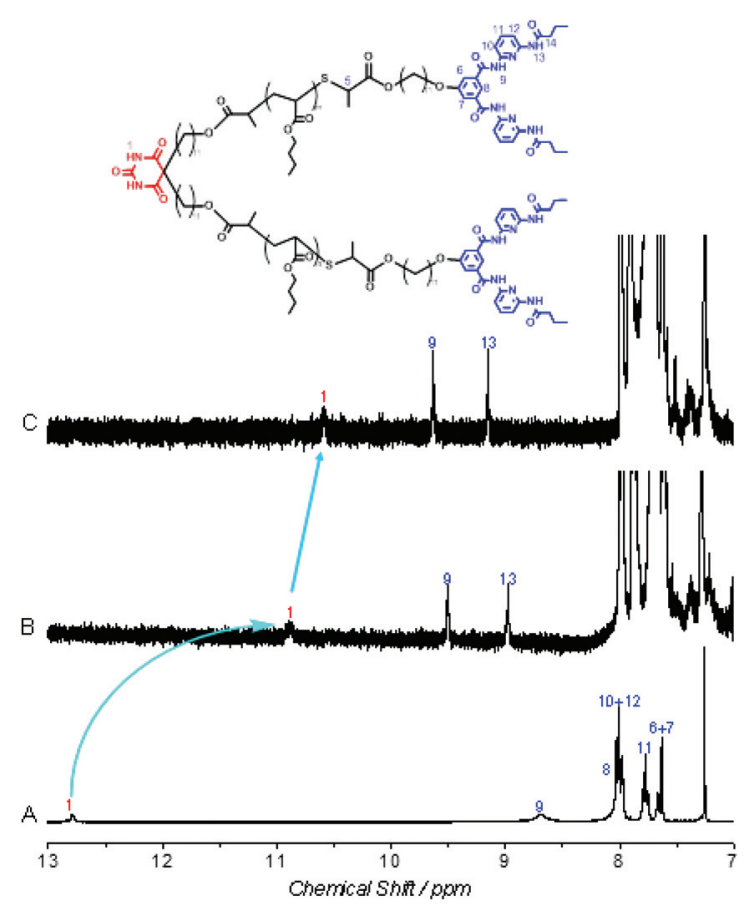

Fig. 5 Partial ${ }^{1} \mathrm{H}$ NMR spectrum of $\mathrm{Ba}-(\mathrm{PnBuA}-\mathrm{HW})_{2}$ recorded in different solvents at $27^{\circ} \mathrm{C}$, $\left[\mathrm{Ba}-(\mathrm{PnBuA}-\mathrm{HW})_{2}\right]=2 \mathrm{mM}$. (A): $\mathrm{CDCl}_{3},(\mathrm{~B})$ :

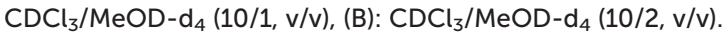

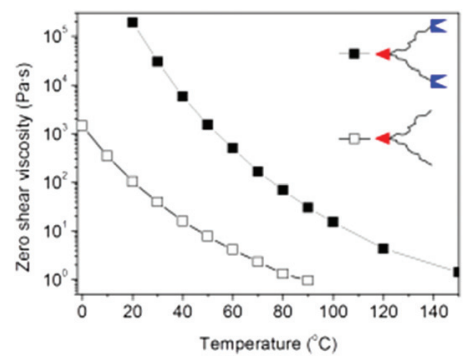

Fig. 6 Zero shear viscosity $\left(\eta_{0}\right)$ vs. temperature for Ba-(PnBuA-RAFT $)_{2}$ (open square), and $\mathrm{Ba}-(\mathrm{PnBuA}-\mathrm{HW})_{2}$ (closed square). 
ation dynamics of supramolecular structures. Thus Ba$(\mathrm{P} n \mathrm{BuA}-\mathrm{RAFT})_{2}$ and $\mathrm{Ba}-(\mathrm{P} n \mathrm{BuA}-\mathrm{HW})_{2}$ are investigated by frequency-dependent measurements at different temperatures (ESI, Fig. S4 $\dagger$ ). The zero shear viscosities $\left(\eta_{0}\right)$ are then plotted as a function of temperature (Fig. 6). As expected, the absolute values of $\eta_{0}$ decrease with increasing temperature in both cases. In comparison to the starting material Ba-(PnBuA-RAFT $)_{2}$, the supramolecular polymer self-assembled from $\mathrm{Ba}-(\mathrm{P} n \mathrm{BuA}-\mathrm{HW})_{2}$ demonstrates impressive viscosity enhancements (at $20^{\circ} \mathrm{C}$ by a factor as high as 1839 ). In comparison, our recently developed supramolecular linear structures ${ }^{49}$ display viscosity enhancements only by a factor of $\sim 42$ at $20{ }^{\circ} \mathrm{C}$ : such striking differences in viscosity enhancements (1839 vs. 42) undoubtedly prove the generation of three-dimensional supramolecular dendritic structures by Ba-(PnBuA-HW $)_{2}$, compared to the one-dimensional supramolecular linear structures generated from same polymer with similar molar mass.

In order to further prove the formation of dendritic associates, we have conducted frequency-dependent melt rheology of
$\mathrm{Ba}-(\mathrm{P} n \mathrm{BuA}-\mathrm{RAFT})_{2}$ and $\mathrm{Ba}-(\mathrm{P} n \mathrm{BuA}-\mathrm{HW})_{2}$ in the temperature ranging from 20 to $70{ }^{\circ} \mathrm{C}$ (ESI, Fig. S5 $\dagger$ ). In all cases, Ba$(\mathrm{P} n \mathrm{BuA}-\mathrm{HW})_{2}$ exhibits much higher storage $\left(G^{\prime}\right)$ and loss $\left(G^{\prime \prime}\right)$ moduli than Ba-(PnBuA-RAFT $)_{2}$ under same conditions (frequency and temperature). Moreover, no intersection of the storage and the loss modulus is observed (ESI, Fig. S5†), indicating the viscous property of the sample, together with small angle X-ray scattering (SAXS) profile which doesn't show any clusters (Fig. S6†), we can exclude supramolecular aggregation or crosslinking (gelation) and thus can prove the formation of nonclustered dendritic supramolecular polymers.

A final insight into the morphology and size of the supramolecular dendrimers formed by $\mathrm{Ba}-(\mathrm{P} n \mathrm{BuA}-\mathrm{HW})_{2}$ is corroborated by AFM investigations (intermittent contact mode in air) exerted from solution. Fig. 7 shows typical AFM images of aggregates, obtained by spin-coating on a silicon wafer from a $\mathrm{Ba}-(\mathrm{P} n \mathrm{BuA}-\mathrm{HW})_{2}$ solution in chloroform or toluene. The presence of supramolecular nanostructures is firstly evidenced using chloroform as solvent (Fig. 7A and B, $c=1 \mathrm{~g} \mathrm{~L}^{-1}$ ): the
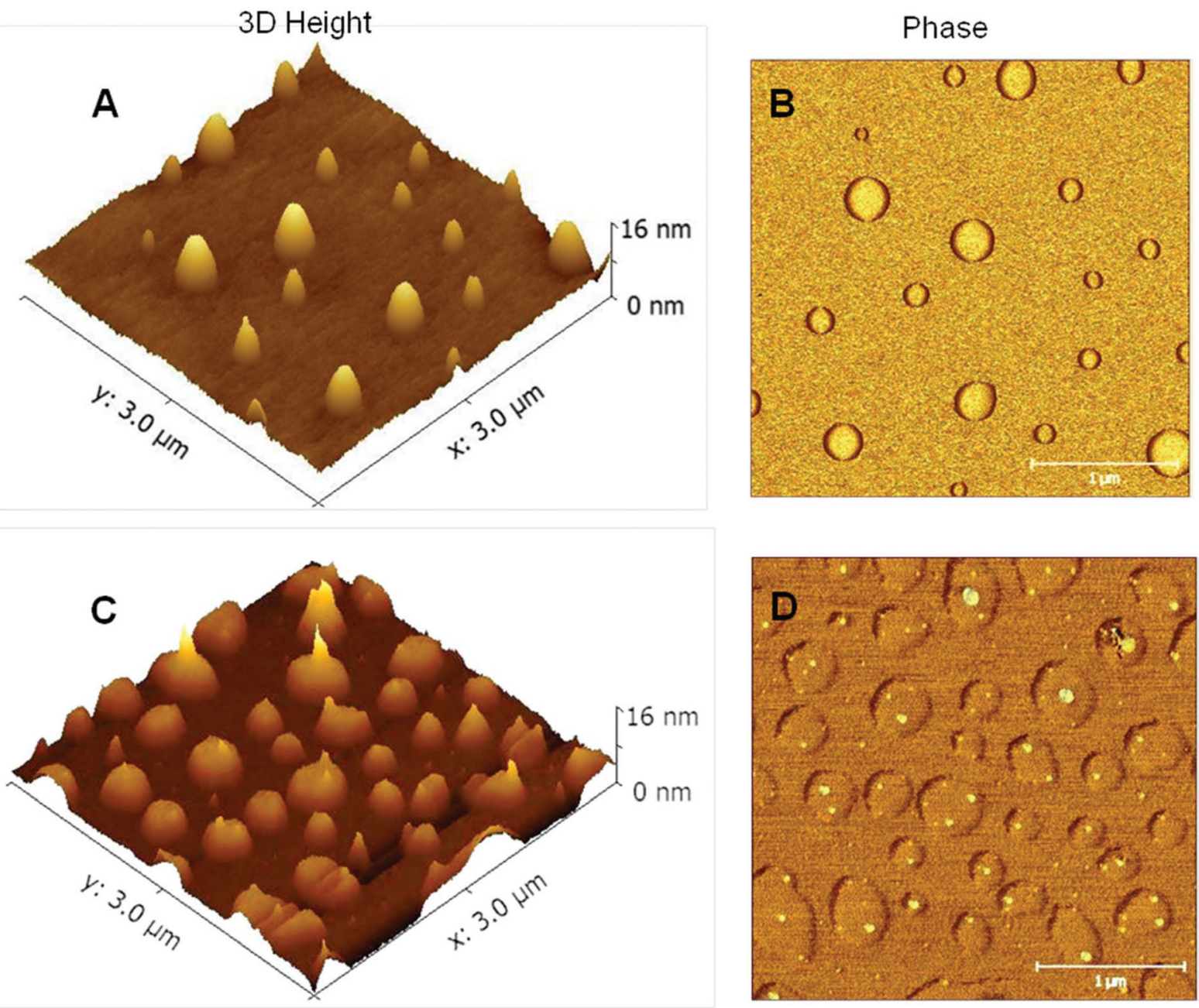

Fig. 7 AFM 3D height (first column) and phase images (second column) of supramolecular aggregates immobilized on a Si solid support by spincoating from a Ba-(PnBuA-HW) solution in $\mathrm{CHCl}_{3}$ (upper row) or toluene (lower row). 
images show defined disc-like objects predominately with diameters $(d)$ of $\sim 180$ and $310 \mathrm{~nm}$, but all of the disc-like objects are remarkably uniform in height (5-6 nm, Fig. 7A, ESI, Fig. S7A and $\mathrm{B} \dagger$ ). In fact, recent reports have demonstrated that the discontinuity in diameter of objects is a striking feature for the presence of high-generation supramolecular dendrimers. ${ }^{31,32}$ While using less polar toluene as solvent at the same concentration, the AFM results exhibit even larger ( $d=\sim 250,340$ and $430 \mathrm{~nm}$ ) disc-like objects (Fig. 7C) with again uniform heights $\left(\sim 5 \mathrm{~nm}\right.$, ESI, Fig. S7C and $\left.\mathrm{D}^{\dagger}\right)$, but a denser surface coverage, explainable by the expected higher degree of association. In addition, diffusion-ordered NMR (DOSY NMR) spectroscopy of a $\mathrm{Ba}-(\mathrm{P} n \mathrm{BuA}-\mathrm{HW})_{2}$ solution in toluene- $\mathrm{d}_{8}$ demonstrates discrete diffusion coefficients which further confirm the differences in the homogeneous size of the selfassembled dendritic supramolecular polymers (ESI, Fig. S8 $\dagger$ ). Interestingly, we also observe elongated nanodomains at the top the discs (Fig. 7C and D, ESI, Fig. S7C and D†), which are harder than the surrounding materials (Fig. 7D, brighter in the corresponding phase image). This interesting hierarchical morphology can be ascribed to the stiff H-bonding aggregates being surrounded by a soft PnBuA polymer matrix. Altogether, the large size of nanoscopic structures observed clearly confirms the presence of dendritic supramolecular polymers formed by the Ba-(PnBuA-HW $)_{2}$. In order to study the influence of polar solvent on the morphology of $\mathrm{Ba}-(\mathrm{P} n \mathrm{BuA}-\mathrm{HW})_{2}$, a mixed solvent system (chloroform/methanol, 1/1, v/v) is used, as seen in Fig. S9. $\uparrow$ The addition of polar methanol result in the complete disappearance of previously obtained disc-like morphology, clearly demonstrating the at least partial dissociation of the supramolecular structures, thus being in agreement with the expected solvent-dependent characteristics of H-bonds.

\section{Conclusions}

Striving to generate supramolecular dendrimers via self-assembly of polymeric building blocks, we have designed $\mathrm{X}-\mathrm{Y}_{2}$ type polymers with appropriate supramolecular endgroups. Benefitting from RAFT-made polymers, the easily available reactive thiol group generated by the aminolysis reaction of dithioester moiety is employed to attach two Hamilton wedges (Y) via a thiol-bromo click reaction in a one-pot two-step synthesis at room temperature within 1 hour. As a result, the mid-barbiturate and $\alpha, \omega$-Hamilton wedge functionalized $\mathrm{X}-\mathrm{Y}_{2}$ type polymer $\mathrm{Ba}-(\mathrm{P} n \mathrm{BuA}-\mathrm{HW})_{2}$ is successfully prepared from Ba$(\mathrm{P} n \mathrm{BuA}-\mathrm{RAFT})_{2}$. Subsequently, supramolecular dendritic polymers are formed through H-bonding self-assembly, illustrating remarkable viscoelastic properties. AFM investigations reveal defined disc-like objects spin-coated from a $\mathrm{Ba}-(\mathrm{P} n \mathrm{BuA}-\mathrm{HW})_{2}$ solution, indicative of the formation of dendritic aggregates. Most importantly, the morphologies of the supramolecular associates have been tuned at the mesoscale by changing the solvent from chloroform to the less polar toluene. The current work expands the scope of the thiol-bromo click reaction, aiding the further construction and potential applications of supramolecular complex structures and hierarchical morphologies.

\section{Acknowledgements}

The authors acknowledge the German Science Foundation, DFG-project BI 1337/7-1 for financial support.

\section{Notes and references}

1 J.-M. Lehn, Proc. Natl. Acad. Sci. U. S. A., 2002, 99, 4763.

2 N. Roy, B. Bruchmann and J.-M. Lehn, Chem. Soc. Rev., 2015, 44, 3786.

3 T. F. A. De Greef, M. M. J. Smulders, M. Wolffs, A. P. H. J. Schenning, R. P. Sijbesma and E. W. Meijer, Chem. Rev., 2009, 109, 5687.

4 T. Aida, E. W. Meijer and S. I. Stupp, Science, 2012, 335, 813.

5 L. Bouteiller, Assembly via Hydrogen Bonds of Low MolarMass Compounds into Supramolecular Polymers, in $A d v$ Polym Sci, 2007, pp. 79-112.

6 W. Binder and R. Zirbs, Supramolecular Polymers and Networks with Hydrogen Bonds in the Main- and Side-Chain, in Adv Polym Sci, 2007, pp. 1-78.

7 A. Bertrand, F. Lortie and J. Bernard, Macromol. Rapid Commun., 2012, 33, 2062.

8 T. Park and S. C. Zimmerman, J. Am. Chem. Soc., 2006, 128, 13986.

9 L. M. Pitet, A. H. M. van Loon, E. J. Kramer, C. J. Hawker and E. W. Meijer, ACS Macro Lett., 2013, 2, 1006.

10 W. H. Binder, S. Bernstorff, C. Kluger, L. Petraru and M. J. Kunz, Adv. Mater., 2005, 17, 2824.

11 S. Chen, M. Rocher, C. Ladaviere, J.-F. Gerard, F. Lortie and J. Bernard, Polym. Chem., 2012, 3, 3157.

12 S. Chen, Y. Deng, X. Chang, H. Barqawi, M. Schulz and W. H. Binder, Polym. Chem., 2014, 5, 2891.

13 D. Montarnal, N. Delbosc, C. Chamignon, M.-A. Virolleaud, Y. Luo, C. J. Hawker, E. Drockenmuller and J. Bernard, Angew. Chem., Int. Ed., 2015, 54, 11117.

14 E. M. Todd and S. C. Zimmerman, J. Am. Chem. Soc., 2007, 129, 14534

15 S. Chen, A. Bertrand, X. Chang, P. Alcouffe, C. Ladaviere, J.-F. Gerard, F. Lortie and J. Bernard, Macromolecules, 2010, 43, 5981.

16 O. Altintas, U. Tunca and C. Barner-Kowollik, Polym. Chem., 2011, 2, 1146.

17 I. Gadwal, S. De, M. C. Stuparu, S. G. Jang, R. J. Amir and A. Khan, J. Polym. Sci., Part A: Polym. Chem., 2012, 50, 2415.

18 O. Altintas, D. Schulze-Suenninghausen, B. Luy and C. Barner-Kowollik, ACS Macro Lett., 2013, 2, 211.

19 S. Pensec, C. Fonteneau and L. Bouteiller, Polym. Chem., 2014, 5, 2496. 
20 S. Catrouillet, C. Fonteneau, L. Bouteiller, N. Delorme, E. Nicol, T. Nicolai, S. Pensec and O. Colombani, Macromolecules, 2013, 46, 7911.

21 S. Pensec, N. Nouvel, A. Guilleman, C. Creton, F. Boue and L. Bouteiller, Macromolecules, 2010, 43, 2529.

22 C.-H. Wong, W.-S. Chan, C.-M. Lo, H.-F. Chow, T. Ngai and K.-W. Wong, Macromolecules, 2010, 43, 8389.

23 N. Roy, E. Buhler and J.-M. Lehn, Polym. Chem., 2013, 4, 2949.

24 P. A. Korevaar, S. J. George, A. J. Markvoort, M. M. J. Smulders, P. A. J. Hilbers, A. P. H. J. Schenning, T. F. A. De Greef and E. W. Meijer, Nature, 2012, 481, 492.

25 P. A. Korevaar, C. J. Newcomb, E. W. Meijer and S. I. Stupp, J. Am. Chem. Soc., 2014, 136, 8540.

26 R. E. Kieltyka, A. C. H. Pape, L. Albertazzi, Y. Nakano, M. M. C. Bastings, I. K. Voets, P. Y. W. Dankers and E. W. Meijer, J. Am. Chem. Soc., 2013, 135, 11159.

27 N. Hosono, A. M. Kushner, J. Chung, A. R. A. Palmans, Z. Guan and E. W. Meijer, J. Am. Chem. Soc., 2015, 137, 6880.

28 R. Dong, Y. Zhou and X. Zhu, Acc. Chem. Res., 2014, 47, 2006.

29 W. T. S. Huck, F. C. J. M. van Veggel, B. L. Kropman, D. H. A. Blank, E. G. Keim, M. M. A. Smithers and D. N. Reinhoudt, J. Am. Chem. Soc., 1995, 117, 8293.

30 F. Huang and H. W. Gibson, J. Am. Chem. Soc., 2004, 126, 14738.

31 A. Franz, W. Bauer and A. Hirsch, Angew. Chem., Int. Ed., 2005, 44, 1564.

32 G. Fernández, E. M. Pérez, L. Sánchez and N. Martín, J. Am. Chem. Soc., 2008, 130, 2410.

33 H. C. Kolb, M. G. Finn and K. B. Sharpless, Angew. Chem., Int. Ed., 2001, 40, 2004.

34 M. Meldal and C. W. Tornøe, Chem. Rev., 2008, 108, 2952.
35 M. A. Gauthier, M. I. Gibson and H.-A. Klok, Angew. Chem., Int. Ed., 2009, 48, 48.

36 R. K. Iha, K. L. Wooley, A. M. Nyström, D. J. Burke, M. J. Kade and C. J. Hawker, Chem. Rev., 2009, 109, 5620.

37 W. H. Binder and R. Sachenshofer, in Click Chemistry for Biotechnology and Materials Science, ed. J. Lahann, WileyBlackwell, 2009, pp. 119-175.

38 C.-H. Wong and S. C. Zimmerman, Chem. Commun., 2013, 49, 1679.

39 W. H. Binder and R. Sachsenhofer, Macromol. Rapid Commun., 2007, 28, 15.

40 M. A. Harvison and A. B. Lowe, Macromol. Rapid Commun., 2011, 32, 779.

41 A. B. Lowe, Polym. Chem., 2014, 5, 4820.

42 B. S. Sumerlin and A. P. Vogt, Macromolecules, 2009, 43, 1.

43 B. M. Rosen, G. Lligadas, C. Hahn and V. Percec, J. Polym. Sci., Part A: Polym. Chem., 2009, 47, 3931.

44 B. M. Rosen, G. Lligadas, C. Hahn and V. Percec, J. Polym. Sci., Part A: Polym. Chem., 2009, 47, 3940.

45 J. Xu, L. Tao, C. Boyer, A. B. Lowe and T. P. Davis, Macromolecules, 2010, 43, 20.

46 S. Samanta, R. Cai and V. Percec, Polym. Chem., 2014, 5, 5479.

47 Y. Zhang, G. Chen, Y. Lin, L. Zhao, W. Z. Yuan, P. Lu, C. K. W. Jim, Y. Zhang and B. Z. Tang, Polym. Chem., 2015, 6, 97.

48 S. Chen, N. Mahmood, M. Beiner and W. H. Binder, Angew. Chem., Int. Ed., 2015, 54, 10188.

49 S. Chen, D. Ströhl and W. H. Binder, ACS Macro Lett., 2015, 4,48 .

50 X. Jiang, P. J. Schoenmakers, X. Lou, V. Lima, J. L. J. van Dongen and J. Brokken-Zijp, J. Chromatogr., A, 2004, 1055, 123. 